\title{
Unresectable Cholangiocarcinoma
}

National Cancer Institute

\section{Source}

National Cancer Institute. Unresectable Cholangiocarcinoma. NCI Thesaurus. Code

C27324.

A cholangiocarcinoma that is not amenable to surgical resection. 